\title{
Stage III Non-Small Cell Lung Cancer in Older Patients: Are We Ready for This Population?
}

\author{
Shinji Atagi \\ Kinki-chuo Chest Medical Center, Osaka, Japan
}

\section{Article Info}

\section{Article Notes}

Received: August 03, 2018

Accepted: January 21, 2019

\section{*Correspondence:}

Dr. Shinji Atagi, MD, Director, Department of Thoracic Oncology, Kinki-chuo Chest Medical Center 1180 Nagasone, Kita-ku,

Sakai, Osaka, 591-8555, Japan;

E-mail: atagi.shinji.pn@mail.hosp.go.jp

(C) 2019 Atagi S. This article is distributed under the terms of the Creative Commons Attribution 4.0 International License.

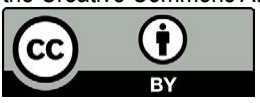

\section{Keywords:}

Elderly

Non-small cell lung cancer

Stage III

Chemoradiotherapy

Comprehensive geriatric assessment.

\section{ABSTRACT}

As of now, concurrent chemoradiotherapy is the treatment of choice for locally advanced stage III non-small cell lung cancer (NSCLC). Older adults continue to be underrepresented in clinical trials, and studies designed specifically for this age group are rare. Prospective elderly-specific trials for locally advanced stage III NSCLC provide little evidence. Older patients are more susceptible to adverse events. A key question is whether elderly patients can receive the same treatments and derive the same benefit as their younger counterparts. The JCOG0301 demonstrated the clinically significant benefits of concurrent daily low-dose carboplatin and thoracic radiotherapies in elderly patients in comparison with those of radiotherapy alone. Recently, durvalumab therapy improved the progression-free survival of patients with unresectable stage III NSCLC whose disease had not progressed after concurrent chemoradiotherapy. Therefore, immune checkpoint inhibitors will also play an increasing role for elderly patients with stage III NSCLC. There are great differences between elderly individuals. Geriatric assessment is recommended to be incorporated in clinical trials. Furthermore, pragmatic clinical trials are required to establish clinical evidence for older patients with a broad range of conditions.

\section{Introduction}

Lung cancer is predominantly a disease of the elderly. More than two-thirds of lung cancer cases occur in persons aged $\geq 65$ years, and the median age at diagnosis is 70 years $^{1}$. Therefore, establishing an effective treatment for elderly patients with lung cancer has become increasingly important. Older adults continue to be underrepresented in clinical trials, and studies designed specifically for this age group are rare $^{2,3}$. Prospective elderly-specific trials for locally advanced stage III non-small cell lung cancer (NSCLC) provide little evidence. As of now, concurrent chemotherapy with radiotherapy (RT) is the proven standard of care for stage III $\mathrm{NSCLC}^{4,5}$. Compared with sequential chemoradiotherapy, concurrent chemoradiotherapy showed an absolute benefit of $4.5 \%$ at 5 years in a meta-analysis ${ }^{6}$. As for the toxicity, the incidence of esophagitis increased. No increase in the risk of pulmonary toxicity was found. Older patients are more susceptible to adverse events. A key question is whether elderly patients can receive the same treatments and derive the same benefit as their younger counterparts.

\section{Pattern of Treatment in the Elderly with Lung Cancer}

The pattern of treatment and survival are largely unknown for older patients with stage III NSCLC. Driessen et al. conducted a population-based study that included unselected patients with stage III NSCLC aged $65-74$ years and $\geq 75$ years and reported patterns 
of treatment and survival in relation to patient and tumor characteristics in the Netherlands ${ }^{7}$. Almost half of the patients aged 65-74 years received chemoradiotherapy, while only one fifth among those aged $\geq 75$ years received chemoradiotherapy. RT alone and best supportive care (BSC) were offered significantly less often for those aged 65-74 years than for those aged $\geq 75$ years (8\% vs $23 \%$ for RT and $13 \%$ vs 33\% for BSC). Okuyama et al. reported the first-course treatment of nine common cancers in patients who received care in designated cancer care hospitals between 2012 and 2015 in Japan ${ }^{8}$. Among the patients with stage III NSCLC, a substantial proportion of patients aged 40-64 years received combination therapy comprising of RT and pharmacotherapy (34.6\%); $<10 \%$ of the patients in the $\geq 85$-year age group received such therapy $(2.3 \%)$. On the other hand, $3.1 \%$ of the patients in the 40 - to 64 -year age group and $51.0 \%$ of those in the $\geq 85$-year age group received no treatment. Consequently, the treatment choices for stage III NSCLC differ according to age. The reason for that is not mentioned in these studies. However, we can infer that the reasons could be physician decision, patient refusal, concomitant medical problems, and caregiver decision (due to cognitive impairment, etc.).

\section{RT Alone for the Elderly}

Thoracic RT alone was the standard treatment for stage III NSCLC. A retrospective examination revealed that a definitive RT of $\geq 60$ Gy was tolerable and feasible in elderly people aged $\geq 75$ years ${ }^{9}$. Pergolizzi et al. conducted a prospective study to evaluate the toxicity and efficacy of definitive RT in very old unfit patients with stage IIIA NSCLC ${ }^{10}$. Forty patients aged $\geq 75$ years with a Karnofsky performance status (PS) score of $\geq 60$ who were unfit to receive an aggressive combined treatment were included in the study. Their median survival time (MST) was 19 months. Their 3- and 5-year survival rates were $18 \%$ and $12 \%$, respectively. Joo et al. reported a retrospective analysis of the effectiveness of RT of $>60$ Gy administered alone in patients with NSCLC who were unfit or rejected for combination treatment ${ }^{11}$. Of the patients, $48 \%$ had an ECOG PS score of 2 or 3. The MST was 18.6 months for all the patients. For the patients with stage II and III NSCLC, the MST was 24.0 and 18.3 months, respectively. RT alone showed promising results. In this study, the patients were treated using modern techniques such as three-dimensional conformal RT (3-D CRT) or intensity-modulated RT (IMRT), involved-field RT, and a dose of >60 Gy.

A highly accurate RT by innovators in RT and the imaging technique is expected to improve the effect and safety profiles.

\section{Comparison between RT Alone and Combination Therapy in the Elderly}

The Japan Clinical Oncology Group (JCOG) trial

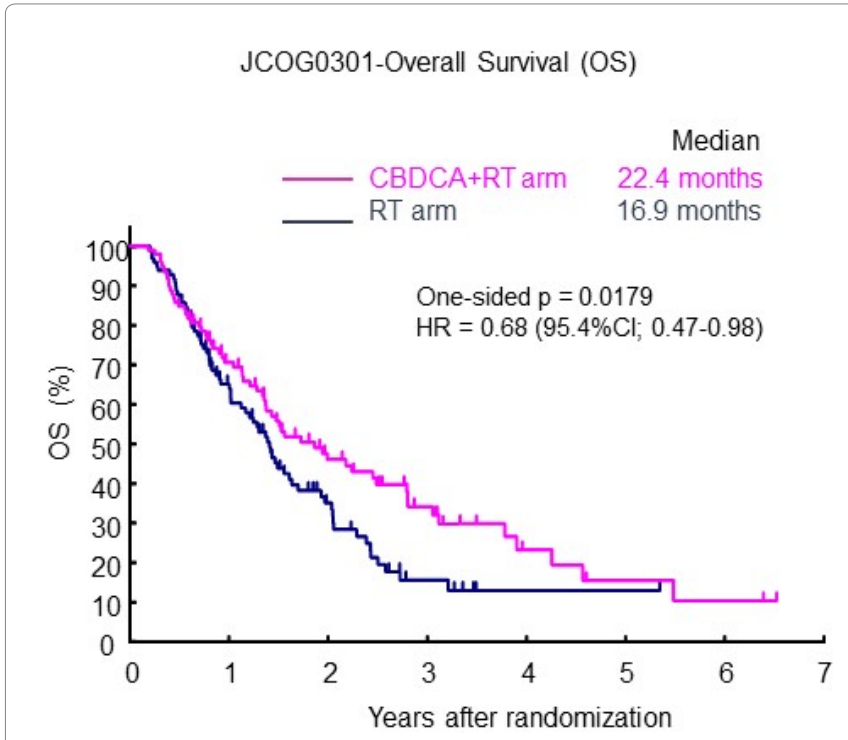

Figure 1: Overall survival curve comparing concurrent chemoradiotherapy with radiotherapy alone for elderly patients in the JCOG0301 trial. (Reprinted from Lancet Oncol. 2012;13:671-678.)

(JCOG0301) was conducted to determine whether daily lowdose carboplatin plus RT has a greater impact than RT alone on the survival of elderly patients with unresectable locally advanced NSCLC ${ }^{12}$. Patients aged $>70$ years with unresectable stage III NSCLC were randomized to receive either RT alone (RT arm) or chemoradiotherapy (CRT arm). The median overall survival (OS) for the RT and CRT arms were 16.9 months (95\% confidence interval [CI], 13.4-20.3 months) and 22.4 months (95\% CI, 16.5-33.6 months), respectively (Figure 1). The OS was significantly more favorable in the CRT arm (hazard ratio[HR], 0.68; 95.4\% CI, 0.47-0.98). In the patients in the CRT arm, leukocytopenia, neutropenia, and thrombocytopenia were more prevalent than in the patients in the RT arm. A higher incidence of infection was observed in the CRT arm, which reflected a higher incidence of neutropenia. However, the infections were manageable with the appropriate treatments. This trial demonstrated the clinically significant benefits of concurrent daily low-dose carboplatin therapy and thoracic RT in elderly patients.

\section{Subgroup Analysis by Age in the Concurrent Chemoradiotherapy Group}

Age-specific subgroup analyses of randomized trials to compare the impact of concurrent chemoradiotherapy have been reported (Table 1). The survival data of these studies showed similarities between the $<70$ - and $\geq 70$ year age groups ${ }^{13-16}$. With regard to toxicities, elderly patients showed higher incidence rates of hematotoxicity and renal failure ${ }^{13}$. Pneumonitis was more frequent in the elderly patients, but grade $\geq 3$ hematotoxicity, esophagitis, and pneumonitis showed no significant differences ${ }^{16}$. 
Table 1. Retrospective subgroup analyses by age in chemoradiotherapy trials for unresectable stage III non-small cell lung cancer.

\begin{tabular}{|c|c|c|c|c|c|c|}
\hline Author & Age & Paients, $N$ & Regimen & Surviv & & Toxicity \\
\hline $\begin{array}{l}\text { Rocha- } \\
\text { Lima }^{13}\end{array}$ & $\begin{array}{l}\geqq 70 \\
<70\end{array}$ & $\begin{array}{l}54(22 \%) \\
196\end{array}$ & $\begin{array}{l}\text { Vinblastine/cisplatin followed by } \\
\text { RT } 60 \text { Gy alone } \\
\text { or } \\
\text { RT } 60 \text { Gy + weekly Carboplatin }\end{array}$ & $\begin{array}{l}\text { Age } \\
<50 \\
50-59 \\
60-69 \\
70-79\end{array}$ & $\begin{array}{l}\text { MST } \\
10.9 \text { months } \\
12.7 \text { months } \\
15.4 \text { months } \\
13.4 \text { months }\end{array}$ & $\begin{array}{l}\text { More granulocyte toxicity and } \\
\text { renal toxicity during induction } \\
\text { chemotherapy among older } \\
\text { patients. }\end{array}$ \\
\hline Schild ${ }^{14}$ & $\begin{array}{l}\geqq 70 \\
<70\end{array}$ & $\begin{array}{l}63(26 \%) \\
181\end{array}$ & $\begin{array}{l}\text { Cisplatin/etoposide with } \\
\text { Once-daily RT } 60 \mathrm{~Gy} \\
\text { or } \\
\text { Twice-daily split course RT } 60 \mathrm{~Gy}\end{array}$ & $\begin{array}{l}\text { Age } \geqq \\
2 \text {-year } \\
5 \text {-year } \\
\text { Age }< \\
2 \text {-year } \\
5 \text {-year }\end{array}$ & $\begin{array}{l}\text { val } 36 \% \\
\text { val } 13 \% \\
\text { val } 39 \% \\
\text { val } 18 \%\end{array}$ & $\begin{array}{l}\text { - Grade } 4+\text { hematologic toxicity } \\
56 \% \text { : age }<70 \text { vs } 78 \% \text { : age } \geq 70 \\
(p=0.003) \\
\text { - Grade } 4+\text { pneumonitis } \\
1 \% \text { : age }<70 \text { vs } 6 \% \text { : age } \geq 70 \text { (p } \\
=0.02)\end{array}$ \\
\hline Jalal|15 & $\begin{array}{l}\geqq 70 \\
<70\end{array}$ & $\begin{array}{l}64(26 \%) \\
179\end{array}$ & $\begin{array}{l}\text { Cisplatin/etoposide+RT } 59.4 \mathrm{~Gy} \\
\text { followed by Docetacel } \\
\text { or } \\
\text { Observation }\end{array}$ & $\begin{array}{l}\text { Age } \geqq \\
\text { Age }<\end{array}$ & $\begin{array}{l}\text { IST } 17.1 \text { months } \\
\text { AST } 22.8 \text { months } \\
\text { = } 0.15)\end{array}$ & $\begin{array}{l}\text { Higher rates of grade } 3-4 \\
\text { neutropenia, dehydration, } \\
\text { anorexia, and fatigue in } \\
\text { older patients. More likely } \\
\text { to be hospitalized during } \\
\text { chemoradiothrapy. }\end{array}$ \\
\hline Takigawa ${ }^{16}$ & $\begin{array}{l}\geqq 70 \\
<70\end{array}$ & $\begin{array}{l}52(26 \%) \\
148\end{array}$ & $\begin{array}{l}\text { Cisplatin/docetaxel+RT } 60 \mathrm{~Gy} \\
\text { or } \\
\text { Mitomycin C/vindesine/cisplatin+RT } \\
60 \mathrm{~Gy}\end{array}$ & $\begin{array}{l}\text { - DP a } \\
\text { Age } \geqq \\
\text { Age }< \\
\text { - MVP } \\
\text { Age } \geqq \\
\text { Age }<\end{array}$ & $\begin{array}{l}\text { IST } 27.5 \text { months } \\
\text { AST } 25.6 \text { months } \\
\text { IST } 22.9 \text { months } \\
\text { AST } 23.4 \text { months }\end{array}$ & $\begin{array}{l}\text { - Grade } 3-5 \text { pneumonitis } \\
\text { DP arm } \\
\text { 8\%: age }<70 \text { vs } 15 \% \text { : age } \geqq 70 \\
\text { MVP arm } \\
5 \% \text { : age }<70 \text { vs } 12 \% \text { : age } \geqq 70\end{array}$ \\
\hline
\end{tabular}

The current standard of care for locally advanced NSCLC is combined concurrent therapy with a platinumbased regimen. A pooled analysis reported that elderly patients had higher toxicity and poorer survival after concurrent chemoradiotherapy ${ }^{17}$. Grade 5 adverse events occurred in $9.0 \%$ of the elderly patients and in $4.4 \%$ of the younger patients. Therefore, whether platinum-doublet chemotherapy is effective and tolerable for a wide range of age groups remains unclear.

\section{Single Agent Chemotherapy with RT in Elderly}

\section{S-1}

S-1 is an oral anticancer agent comprising of tegafur, gimeracil, and oteracil at a molar ratio of 1:0.4:118. A phase II study of oral S-1 as a single agent for the treatment of advanced NSCLC yielded a response rate of $22 \%$ and a MST of 10.2 months $^{19}$. Recently, S-1 is equally as efficacious as docetaxel therapy for patients with previously treated advanced NSCLC ${ }^{20}$. The preclinical synergistic activity of S-1 with RT and its favorable toxicity profile have led to clinical trials that evaluated S-1 in chemoradiotherapy regimens in elderly patients mainly in Japan (Table 2). The Okayama lung cancer study group conducted phase I and II studies of S-1 with thoracic RT in elderly patients aged $\geq 76$ years ${ }^{21,22}$. In the phase II study, 30 patients were enrolled, the response rate was $63 \%$ and the MST was 27.9 months.

Hasegawa et al. reported a phase I study of S-1 with concurrent RT in elderly patients aged $\geq 70$ years $^{23}$. The overall response rate was $83.3 \%$, and the MST was 34.0 months.

\section{Vinorelbine, pemetrexed}

Single-agent of pemetrexed or vinorelbine for use in concurrent RT have been investigated in elderly patients with stage III NSCLC ${ }^{24,25}$. These combinations seem not feasible for elderly patients because of a high incidence of sever pneumonitis.

\section{Carboplatin doublet combination}

The efficacy of doublet drug in combination with RT in elderly patients was investigated. A retrospective analysis of weekly administration of paclitaxel and carboplatin with

Table 2. Summary of clinical studies investigating single agent chemotherapy with radiotherapy in elderly.

\begin{tabular}{|l|c|c|c|c|c|c|c|}
\hline Author & Phase & Patients, N & Age & Regimen & RT (Gy) & RR (\%) & Median OS (months) \\
\hline Atagi $^{12}$ & III & 100 & $>70$ & CBDCA+RT & 60 & 51.5 & 22.4 \\
\hline Takigawa $^{21}$ & I & 22 & $>75$ & S-1+RT & 60 & 75.5 & 34.1 \\
\hline Aoe $^{22}$ & II & 30 & $>75$ & S-1+RT & 60 & 63 & 27.9 \\
\hline Hasegawa $^{23}$ & I & 12 & $\geqq 70$ & S-1 + RT & 60 & 83.3 & 34.0 \\
\hline OS: overall survival, CBDCA: carboplatin, RT: radiotherapy, RR: response rate \\
\hline
\end{tabular}


concurrent RT in patients aged $\geq 75$ years was reported ${ }^{26}$. The response rate was $90 \%$, and the median OS was 16.1 months. Although this combination regimen demonstrated good feasibility and safety, a clinically significant survival benefit was not provided. Niho et al. reported a phase II study of carboplatin, S-1, and thoracic RT for elderly patients with locally advanced NSCLC ${ }^{27}$. Twenty-eight patients were enrolled in this study. The median age was 77 years (range, 71-83 years). The response rate was $71.4 \%$. The median OS was 25.0 months. Grade $\geq 3$ pneumonitis was $18 \%$. Although carboplatin plus S-1 and concurrent thoracic RT had promising efficacy in elderly patients with locally advanced NSCLC, radiation pneumonitis was frequently observed with the therapy as compared with single-agent chemotherapy carboplatin or S-1.

\section{Cetuximab}

A phase II study of cetuximab and RT in the elderly and/or patients with poor performance status was reported. In this study, patients aged $\geq 65$ years with an ECOG PS score of 0-2 and patients aged $<65$ and $\geq 18$ years with a PS score of 2 were evaluated $^{28}$. The response rate was $26 \%$. The median survival was 15.1 months (95\% CI, 5.8-8.6). No treatment-related deaths occurred, but 31 (53.4\%) of 58 patients experienced grade $\geq 3$ adverse events. The RTOG 0617 phase III trial investigated the use of cetuximub with standard and highdose chemoradiotherapy ${ }^{29}$. This trial recruited patients aged $\geq 18$ years. It was not an elderly-specific trial. The addition of cetuxumab to chemoradiotherapy did not provide any survival benefit while increasing toxicities.

\section{Emerging Immunotherapy in Stage III NSCLC}

Durvalumab is a fully human IgG1 monoclonal antibody that blocks PD-L1 ${ }^{30}$. The PACIFIC study assessed the efficacy of durvalumab as a consolidation therapy in comparison with a placebo in patients with stage III, locally advanced, unresectable NSCLCs after platinum-based chemoradiotherapy ${ }^{31}$. The median PFS was 16.8 months with durvalumab and 5.6 months with placebo (HR, 0.52; $\mathrm{P}<0.001)$. The safety profile was similar between the arms. The most common grade 3 or 4 adverse event was pneumonia $(4.4 \%$ in the durvalumab arm vs $3.8 \%$ in the placebo arm). A subgroup analysis revealed a PFS benefit with durvalumab across all prespecified prognostic factors. The HR by age was 0.43 (95\% CI, $0.32-0.57)$ in the $<65$ year age group and 0.74 (95\% CI, $0.54-1.01$ ) in the $\geq 65$ year age group. Therefore, immune checkpoint inhibitors will also play an increasing role in the treatment for elderly patients with stage III NSCLC. Attention must be paid to immune-mediated adverse events.

\section{Integration of Geriatric Assessment into Clinical} Trials and Practice

There are great differences between elderly individuals.
Diagnostic tools are needed to accurately judge the status of elderly patients to identify the suitable treatment. The ASCO guideline states that the Comprehensive Geriatric Assessment (CGA) should be used to identify vulnerabilities that are not routinely captured in oncology assessments in patients aged $\geq 65$ years who are receiving chemotherapy ${ }^{32}$. Antonio etal. reported the results of a prospective study that assessed the value of geriatric assessment in elderly patients with stage III NSCLC for concurrent chemoradiotherapy ${ }^{33}$. Geriatric assessment and the Vulnerable Elders Survey (VES-13) may help in the selection of elderly patients for concurrent chemoradiotherapy to avoid undertreatment of eligible elderly patients, as VES-13 has been shown to be significantly associated with a higher risk of toxicity. Locher et al. reported an open phase II study that used concurrent cisplatin-oral vinorelbine and $\mathrm{RT}^{34}$. In this study, elderly patients (aged $>70$ years) with unresectable stage III NSCLCs were selected on the basis of the inclusion and exclusion criteria. In addition, patients must be certified fit by CGA. The authors concluded that CGA may help to select fit elderly patients eligible for standard chemoradiotherapy with a satisfactory risk-to-benefit ratio. The NVALT25ELDAPT trial is ongoing to develop a reliable and clinically applicable screening tool to distinguish medically fit individuals from frail patients ${ }^{35}$. From the results of this study, treatment selection can be optimized and the best possible outcomes for each individual older patients with stage III NSCLC can be achieved.

\section{Future Prospects}

In the subject of oncology regarding older and vulnerable patients, it is important to avoid over treatment and under treatment. A recommended approach is patient selection using tools such as CGA. If we can divide elderly patients into subgroups by using geriatric assessment, elderly patients can be given appropriate treatments according to their conditions.

Randomized controlled trials usually have stringent inclusion and exclusion criteria, and only highly selected elderly patients can enroll in these clinical trials. However, many elderly people with cancer are unable to participate because of comorbidities, organ dysfunction, their general conditions, and so on. To investigate a wide range of older and less fit adults with cancer, pragmatic clinical trials that enable broad eligibility; treatment modification based on clinical necessity; and representation of more meaningful clinical endpoints, rather than hard endpoints, are required $^{36,37}$. Therefore, pragmatic clinical trials with realworld effectiveness that is relevant to the general older population with cancer should be established.

\section{References}

1. SEER Cancer Statistics Cancer of All Sites - SEER Stat Fact Sheets. Available at: http://seer.cancer.gov/statfacts/html/lungb.html access (accessed Jul 27, 2018). 
2. Hutchins LF, Unger JM, Crowley JJ, et al. Underrepresentation of patients 65 years of age or older in cancer-treatment trials. $\mathrm{N}$ Engl J Med. 1999; 30; 341(27):2061-2067.

3. Jennens RR, Giles GG, Fox RM. Increasing underrepresentation of elderly patients with advanced colorectal or non-small-cell lung cancer in chemotherapy trials. Intern Med J. 2006; 36(4): 216-220.

4. Furuse K, Fukuoka M, Kawahara M, et al. Phase III study of concurrent versus sequential thoracic radiotherapy in combination with mitomycin, vindesine, and cisplatin in unresectable stage III nonsmall-cell lung cancer. J Clin Oncol. 1999; 17(9): 2692-2699.

5. Curran WJ Jr, Paulus R, Langer CJ, et al. Sequential vs Concurrent Chemoradiation for Stage III Non-Small Cell Lung Cancer: Randomized Phase III Trial RTOG 9410. J Natl Cancer Inst. 2011; 103(19): 14521460.

6. Aupérin A, Le Péchoux C, Rolland E, et al. Meta-analysis of concomitant versus sequential radiochemotherapy in locally advanced non-smallcell lung cancer. J Clin Oncol. 2010; 28(13): 2181-2190.

7. Driessen EJM, Schulkes KJG, Dingemans AC, et al. Patterns of treatment and survival among older patients with stage III non-small cell lung cancer. Lung Cancer. 2018; 116: 55-61.

8. Okuyama A, Higashi T. Patterns of cancer treatment in different age groups in Japan: an analysis of hospital-based cancer registry data, 2012-2015. Jpn J Clin Oncol. 2018; 48(5): 417-425.

9. Hayakawa K, Mitsuhashi N, Katano S, et al. High-dose radiation therapy for elderly patients with inoperable or unresectable nonsmall cell lung cancer. Lung Cancer. 2001; 32(1): 81-88.

10. Pergolizzi S, Santacaterina A, Renzis CD, et al. Older people with non small cell lung cancer in clinical stage IIIA and co-morbid conditions. Is curative irradiation feasible? Final results of a prospective study. Lung Cancer. 2002; 37(2): 201-206.

11. Joo JH, Song SY, Kim SS, et al. Definitive radiotherapy alone over $60 \mathrm{~Gy}$ for patients unfit for combined treatment to stage II-III non-small cell lung cancer: retrospective analysis. Radiat Oncol. 2015; 10: 250.

12. Atagi S, Kawahara M, Yokoyama A, et al. Thoracic radiotherapy with or without daily low-dose carboplatin in elderly patients with nonsmall-cell lung cancer: a randomised, controlled, phase 3 trial by the Japan Clinical Oncology Group (JCOG0301). Lancet Oncol. 2012 13(7): 671-678,

13. Rocha Lima CM, Herndon JE 2nd, Kosty M, et al. Therapy choices among older patients with lung carcinoma: an evaluation of two trials of the Cancer and Leukemia Group B. Cancer. 2002; 94(1): 181-187.

14. Schild SE, Stella PJ, Geyer SM, et al. The outcome of combined-modality therapy for stage III non-small-cell lung cancer in the elderly. J Clin Oncol. 2003; 21(17): 3201-3206.

15. Jalal SI, Riggs HD, Melnyk A, et al. Updated survival and outcomes for older adults with inoperable stage III non-small-cell lung cancer treated with cisplatin, etoposide, and concurrent chest radiation with or without consolidation docetaxel: analysis of a phase III trial from the Hoosier Oncology Group (HOG) and US Oncology. Ann Oncol. 2012; 23(7): 1730-1738.

16. Takigawa N, Kiura K, Segawa Y, et al. Benefits and adverse events among elderly patients receiving concurrent chemoradiotherapy for locally advanced non-small cell lung cancer: analysis of the Okayama Lung Cancer Study Group trial 0007. J Thorac Oncol. 2011; 6(6): 1087-1091.

17. Stinchcombe TE, Zhang Y, Vokes EE, et al. Pooled Analysis of Individual Patient Data on Concurrent Chemoradiotherapy for Stage III NonSmall-Cell Lung Cancer in Elderly Patients Compared With Younger Patients Who Participated in US National Cancer Institute Cooperative Group Studies. J Clin Oncol. 2017; 35(25): 2885-2892.

18. Shirasaka T, Nakano K, Takechi T, et al. Antitumor activity of $1 \mathrm{M}$ tegafur-0.4 M 5-chloro-2,4-dihydroxypyridine-1 M potassium oxonate (S-1) against human colon carcinoma orthotopically implanted into nude rats. Cancer Res. 1996; 56(11): 2602-2606.

19. Kawahara M, Furuse K, Segawa Y, et al: Phase II study of S-1, a novel oral fluorouracil, in advanced non-small-cell lung cancer. Br J Cancer. 2001; 85(7): 939-943.

20. Nokihara H, Lu S, Mok TSK, et al. Randomized controlled trial of S-1 versus docetaxel in patients with non-small-cell lung cancer previously treated with platinum-based chemotherapy (East Asia S-1 Trial in Lung Cancer). Ann Oncol. 2017; 28(11): 2698-2706.

21. Takigawa N, Kiura K, Hotta K, et al. A phase I study of S-1 with concurrent thoracic radiotherapy in elderly patients with localized advanced non-small cell lung cancer. Lung Cancer. 2011; 71(1): 60-64.

22. Aoe K, Takigawa N, Hotta K, et al. A phase II study of S-1 chemotherapy with concurrent thoracic radiotherapy in elderly patients with locally advanced non-small-cell lung cancer: the Okayama Lung Cancer Study Group Trial 0801. Eur J Cancer. 2014; 50(16): 2783-2790,.

23. Hasegawa Y, Okamoto I, Takezawa K, et al. A phase I study of S-1 with concurrent radiotherapy in elderly patients with locally advanced non-small cell lung cancer. Invest New Drugs. 2013; 31(3): 599-604.

24. Harada $\mathrm{H}$, Seto T, Igawa $\mathrm{S}$, et al. Phase I results of vinorelbine with concurrent radiotherapy in elderly patients with unresectable, locally advanced non-small-cell lung cancer: West Japan Thoracic Oncology Group (WJTOG3005-DI). Int J Radiat Oncol Biol Phys. 2012; 82(5): 1777-1782.

25. Tamiya A, Morimoto M, Fukuda S, et al. A phase I/II trial of pemetrexed plus radiotherapy in elderly patients with locally advanced non-small cell lung cancer. Invest New Drugs. 2018; 36(4): 667-673.

26. Takeshita J, Masago K, Fujita S, et al: Weekly administration of paclitaxel and carboplatin with concurrent thoracic radiation in previously untreated elderly patients with locally advanced nonsmall-cell lung cancer: A case series of 20 patients. Mol Clin Oncol. 2014; 2(3): 454-460.

27. Niho S, Umemura S, Hosomi Y, et al. Carboplatin (CBDCA), S-1 and concurrent thoracic radiotherapy (TRT) for elderly patients with locally advanced non-small cell lung cancer (NSCLC): A phase II study. J Clin Oncol. 2018; 36(suppl 8530).

28. Jatoi A, Schild SE, Foster N, et al. A phase II study of cetuximab and radiation in elderly and/or poor performance status patients with locally advanced non-small-cell lung cancer (N0422). Ann Oncol. 2010; 21(10): 2040-2044.

29. Bradley JD, Paulus R, Komaki R, et al. Standard-dose versus highdose conformal $r$ adiotherapy with concurrent and consolidation carboplatin plus paclitaxel with or without cetuximab for patients with stage IIIA or IIIB non-small-cell lung cancer (RTOG 0617): a randomised, two-by-two factorial phase 3 study. Lancet Oncol. 2015; 16(2): 187-199.

30. Stewart R, Morrow M, Hammond SA, et al. dentification and Characterization of MEDI4736, an Antagonistic Anti-PD-L1 Monoclonal Antibody. Cancer Immunol Res. 2015; 3(9): 1052-1062.

31. Antonia SJ, Villegas A, Daniel D, et al. Durvalumab after Chemoradiotherapy in Stage III Non-Small-Cell Lung Cancer. N Engl J Med. 2017; 377(20): 1919-1929.

32. Mohile SG, Dale W, Somerfield MR, et al. Practical Assessment and Management of Vulnerabilities in Older Patients Receiving Chemotherapy: ASCO Guideline for Geriatric Oncology. J Clin Oncol. 2018; 36(22): 2326-2347.

33. Antonio M, Saldaña J, Linares J, et al. Geriatric assessment may help decision-making in elderly patients with inoperable, locally advanced non-small-cell lung cancer. Br J Cancer. 2018; 118(5): 639-647.

34. Locher C, Pourel N, Le Caer H, et al. Impact of a comprehensive 
geriatric assessment to manage elderly patients with locally advanced non-small-cell lung cancers: An open phase II study using concurrent cisplatin-oral vinorelbine and radiotherapy (GFPC 08-06). Lung Cancer. 2018; 121: 25-29.

35. Driessen EJM, Janssen-Heijnen MLG, Maas HA, et al. Study protocol of the NVALT25-ELDAPT trial: Selecting the optimal treatment for older patients with stage III non-small cell lung cancer. Clin Lung Cancer.
Published online: July 09, 2018. DOI: https://doi.org/10.1016/j. cllc.2018.07.003

36. Ware JH, Hamel MB. Pragmatic trials--guides to better patient care? N Engl J Med. 2011; 364(18): 1685-1687.

37. Nipp RD, Yao NA, Lowenstein LM, et al. Pragmatic study designs for older adults with cancer: Report from the U13 conference. J Geriatr Oncol. 2016; 7(4): 234-241. 